\title{
Potato Root Diffusate-Induced Secretion of Soluble, Basic Proteins Originating from the Subventral Esophageal Glands of Potato Cyst Nematodes
}

\author{
Geert Smant, Aska Goverse, Jack P. W. G. Stokkermans, Jan M. De Boer, \\ H. (Rikus) Pomp, Jacoline F. Zilverentant, Hein A. Overmars, Johannes Helder, Arjen Schots, and Jaap Bakker
}

Department of Nematology, Wageningen Agricultural University, P.O. Box 8213, 6700 ES Wageningen, the Netherlands. Current address of J. M. De Boer: Department of Plant Pathology, Iowa State University, 351 Bessey Hall, Ames 50011-1020. Accepted for publication 2 May 1997.

\begin{abstract}
Smant, G., Goverse, A., Stokkermans, J. P. W. G., De Boer, J. M., Pomp, H., Zilverentant, J. F., Overmars, H. A., Helder, J., Schots, A., and Bakker, J. 1997. Potato root diffusate-induced secretion of soluble, basic proteins originating from the subventral esophageal glands of potato cyst nematodes. Phytopathology 87:839-845.

In preparasitic second-stage juveniles $\left(\mathrm{J}_{2}\right)$ of potato cyst nematode Globodera rostochiensis, six proteins with molecular masses of 30, $31 \mathrm{a} / \mathrm{b}, 32,39$, and $49 \mathrm{kDa}$ were recognized on Western blots by a monoclonal antibody (MGR48) specific for the subventral esophageal glands. All of these subventral gland proteins (svp's) focused in the basic range (pI 6.8 to 8.6) of an immobilized $\mathrm{pH}$ gradient. Western blotting

that the svp's were localized in the rough endoplasmic reticulum and secretory granules of the subventral esophageal glands. Potato root diffusate triggered the secretion of svp's through the stylet, and 5-methoxy$\mathrm{N}, \mathrm{N}$-dimethyltryptamine-hydrogen-oxalate had only a quantitative, additional effect. The forward flow of svp's through the metacorporal pump chamber was confirmed by the presence of svp's in the circular lumen of the esophagus (procorpus), as established by immunoelectron microscopy. Our data provide conclusive evidence that secretory proteins of the subventral glands of G. rostochiensis can be secreted through the stylet and support the hypothesis that the subventral esophageal glands play an important role in the early events of this nematode-plant interaction.
\end{abstract} showed that the svp's were present in preparasitic and parasitic $\mathrm{J}_{2}$ and not in later juvenile stages and adult females. Minor svp quantities also were observed in adult males. Immunogold labeling of preparasitic $\mathrm{J}_{2}$ showed
Additional keywords: plant-parasite interaction, secretory pathway.
Cyst nematodes, Heterodera and Globodera spp., have evolved highly specialized and complex feeding relationships with their host plants. After penetration behind growing root tips, second-stage juveniles $\left(\mathrm{J}_{2}\right)$ migrate intracellularly toward the vascular cylinder and become immobile after the induction of an initial syncytial cell opposite a protoxylem pole. Cells adjacent to the initial syncytial cell are incorporated into the expanding syncytium by partial dissolution of the cell walls. The central vacuole of the syncytial cells is divided into small secondary vacuoles, and the proliferation of mitochondria, Golgi bodies, plastids, and endoplasmic reticulum indicate a dramatic enhancement of cell metabolism $(17,18,20,24)$. The expansion of the syncytium is accompanied by the activation of the promoters of the cell-cycle genes $c y c l A t$ and $c d c 2 a(21)$ and increased synthesis of DNA (10).

Nematode esophageal gland secretions are thought to play an important role in the host-parasite interaction $(15,17)$. Cyst nematodes have three large esophageal gland cells: one dorsal and two subventral. The dorsal gland has a long cytoplasmic extension that terminates in an ampulla, a reservoir for secretory granules. The ampulla is connected, via a sclerotized duct with an elaborate valve, with the esophageal lumen just behind the stylet knobs $(11,12)$. The release of the secretions at the base of the stylet indicates that passenger molecules from the secretory granules formed in the dorsal gland probably can be secreted through the

Corresponding author: G. Smant

E-mail address: geert.smant@medew.nema.wau.nl

Publication no. P-1997-0604-01R

(C) 1997 The American Phytopathological Society stylet and, as a consequence, can be involved in the host-parasite interaction.

The direction in movement of the secretions released from the two subventral glands is less clear, and the biological role of the secretions has been the subject of speculation. The subventral esophageal glands terminate in ampullae within the esophagus, located posterior to the metacorporal pump chamber (11). It has been argued that the metacorporal pump chamber of cyst nematodes, and also of root-knot nematodes, acts as an unidirectional valve that precludes forward flow $(9,32,34)$. It, therefore, has been suggested that subventral gland secretions are transported solely posteriorly and are involved in intracorporal digestion (9) or mobilization of lipid reserves (33).

Various artificial agents are used to obtain stylet secretions from plant-parasitic nematodes in vitro $(4,5,14,19)$. For example, the serotonin analogue, 5-methoxy- $N, N$-dimethyltryptamine-hydrogenoxalate (DMT), induces stylet secretions, which are precipitated at the lip region $(4,14)$. Also, secretions from the subventral glands have been observed in these precipitates. Using monoclonal antibodies (MAbs), Goverse et al. (14) showed that antigens from the subventral glands of preparasitic $\mathrm{J}_{2}$ of $H$. glycines are present in DMT-induced stylet secretions. Comparable results for subventral esophageal gland proteins were obtained with Meloidogyne incognita, using resorcinol as the inducing agent of stylet secretions (5). However, the biological relevance of chemically induced stylet secretions remains to be established.

Detailed information on the nature of stylet secretions of plantparasitic nematodes is essential for understanding the complex feeding behavior of plant-parasitic nematodes. However, the minute size, long life cycle, and obligate biotrophy of plant-parasitic nematodes has hampered isolation of the substantial quantities of stylet 
secretions required for biochemical analysis and characterization (13). During the last decade, research on stylet secretions focused on generating MAbs against the secretory granules within the esophageal glands. Various panels of MAbs have been raised against stylet secretions of $H$. glycines (14), $H$. avenae (4), G. rostochiensis (Wollenweber) Skarbilovich (8), and M. incognita $(5,6)$. However, biochemical information on the corresponding antigens is scarce. So far, the most detailed information on secretory proteins comes from a MAb specific for the dorsal esophageal glands of preparasitic $\mathrm{J}_{2}$ and adult females of $M$. incognita. This MAb recognizes a large molecular weight glycoprotein $\left(M_{\mathrm{r}}>\right.$ $212,000)$, as established by its slow electrophoretic migration in sodium dodecyl sulfate-polyacrylamide gel electrophoresis (SDSPAGE) and positive staining with periodic acid-Schiff reagent (16).

To study the secretory pathway of proteins from the subventral esophageal glands of $G$. rostochiensis, we used a MAb (MGR48) that recognizes six subventral gland proteins (svp's). The secretion of these proteins through the stylet was stimulated by potato root diffusate (PRD), and their precipitation at the lip region was $\mathrm{pH}$ dependent. In addition, we show that the synthesis of these secretory proteins is under stringent developmental regulation.

\section{MATERIALS AND METHODS}

Nematodes. G. rostochiensis pathotype $\mathrm{Ro}_{1}$ was used in all experiments. Nematodes were reared and hatched as described previously $(7,25)$. When diapause is completed, a minority of $\mathbf{J}_{2}$ will spontaneously hatch when hydrated in tap water. The resulting $\mathbf{J}_{2}$ are termed tap water-hatched $\mathrm{J}_{2}$. When eggs are incubated in PRD (3), the majority of the $\mathrm{J}_{2}$ will hatch. These $\mathrm{J}_{2}$ are termed PRDhatched $\mathrm{J}_{2}$.

Samples of parasitic $\mathrm{J}_{2}$ were collected from infected potato roots 10 to 13 days postinoculation. Plant roots were cut into $1-\mathrm{cm}$ pieces and processed for $30 \mathrm{~s}$ in a blender, and juveniles were separated from root debris by sieving and centrifugation in a $35 \%$ $(\mathrm{wt} / \mathrm{vol}$ ) sucrose solution at $1,000 \times g$ for $5 \mathrm{~min}$. Mixed third-stage male and female juveniles $\left(\mathrm{J}_{3}\right)$ were collected 16 days postinoculation, whereas mixed third and fourth $\left(\mathrm{J}_{4}\right)$ stage females were collected 19 days postinoculation. Adult males and females were obtained 25 and 35 days postinoculation, respectively, as described by De Boer et al. (7). Eggs with young $\mathbf{J}_{2}$ were collected from

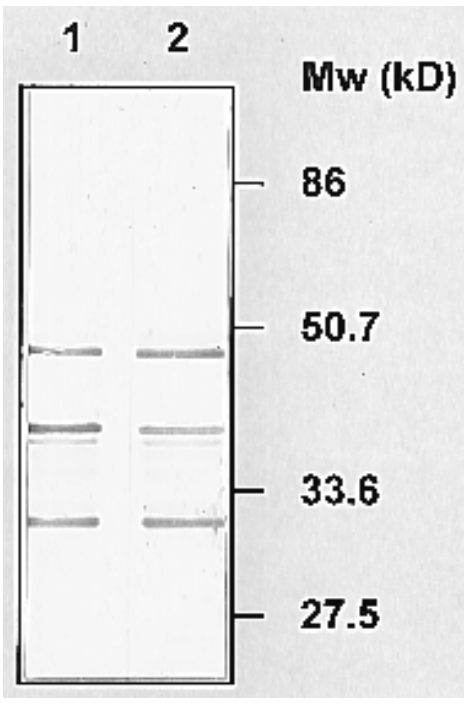

Fig. 1. Western blot of sodium dodecyl sulfate-extracted proteins from preparasitic second-stage juveniles of Globodera rostochiensis after incubation in periodic acid. The experimental lane (lane 2) was treated with $50 \mathrm{mM}$ periodic acid in sodium acetate buffer $(\mathrm{pH} 4.5)$ to allow oxidation of carbohydrate side chains. Compared to the control lane (lane 1), no reduction in labeling intensity was observed with monoclonal antibody MGR48. females at 2 months postinoculation. Eggs containing $\mathbf{J}_{2}$ in diapause were collected from dry cysts.

Protein extraction and SDS-PAGE. SDS-extracted proteins from PRD-hatched $\mathrm{J}_{2}$ of $G$ rostochiensis were obtained by homogenization in $10 \mathrm{mM}$ sodium phosphate buffer, $\mathrm{pH}$ 7.2, with a 2-ml Potter-Elvehjem (Tamson, Fisher Scientific, Springfield, IL) homogenizer with a Teflon pestle. Samples were supplemented with 1 volume of SDS sample buffer (125 mM Tris-HCl [pH 6.8], 4\% [wt/vol] SDS, 10\% [vol/vol] 2-mercaptoethanol, 20\% [vol/vol] glycerol, and $0.05 \%$ [wt/vol] bromophenol blue). The samples were heated in boiling water for $5 \mathrm{~min}$ and centrifuged for $5 \mathrm{~min}$ at $14,000 \times g$. For nonreducing SDS-PAGE, 2-mercaptoethanol was omitted from the sample buffer. Protein concentrations were determined by the bicinchoninic acid assay with bovine serum albumin (BSA) as a standard (Pierce Ltd., Rockford, IL). Analytical SDS-PAGE and immunodetection with MAb MGR48 hybridoma culture supernatant was performed essentially as described by De Boer et al. (7). Prestained SDS-PAGE standards (Bio-Rad Laboratories, Richmond, CA) were used in each run.

Two-dimensional gel electrophoresis. Fresh PRD-hatched $\mathbf{J}_{2}$ of $G$. rostochiensis were homogenized in $1 \%$ (vol/vol) Nonidet P40 (Bio-Rad) and 2\% (vol/vol) 2-mercaptoethanol. Protein concentration was estimated according to the method of Bradford (2), using BSA as the standard. Shortly before isoelectric focusing (IEF) gel electrophoresis, 5 volumes of $8 \mathrm{M}$ urea, $0.5 \%$ (vol $/ \mathrm{vol}$ ) Nonidet P-40, 2\% (vol/vol) 2-mercaptoethanol, 2\% (vol/vol) carrier ampholytes (pH 3 to 10; Bio-Rad), $1 \mathrm{mM}$ Pefabloc (Boehringer $\mathrm{GmbH}$, Mannheim, Germany), and $0.025 \%$ (wt/vol) bromophenol blue were added to the sample. This solution was mixed thoroughly, incubated for $1 \mathrm{~h}$ at room temperature, and centrifuged for $10 \mathrm{~min}$ at $14,000 \times \mathrm{g}$. In the first dimension, $15 \mu \mathrm{g}$ of a total protein extract was separated by IEF on an immobilized $\mathrm{pH} 3$ to 10 gradient (Immobiline dry strips 3-10L, Pharmacia LKB Biotechnology, Upsala, Sweden). The immobilized $\mathrm{pH}$ gradient strips with focused proteins were equilibrated for $15 \mathrm{~min}$ in $10 \mathrm{ml}$ of freshly prepared $50 \mathrm{mM}$ Tris- $\mathrm{HCl}(\mathrm{pH} 6.8), 4.17 \mathrm{M}$ urea, 30\% (vol/vol) glycerol, $1 \%$ (wt/vol) SDS, and $16.2 \mathrm{mM}$ dithiothreitol; were equilibrated for $15 \mathrm{~min}$ in $10 \mathrm{ml}$ of $50 \mathrm{mM}$ Tris- $\mathrm{HCl}(\mathrm{pH}$ 6.8), 4.17 M urea, 30\% (vol/vol) glycerol, 1\% (wt/vol) SDS, 240

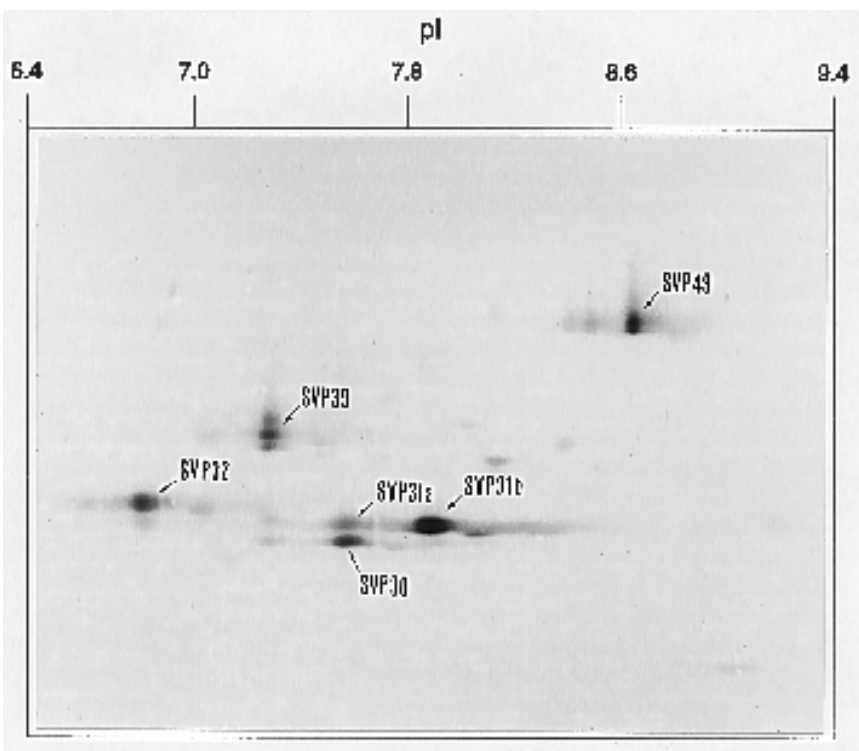

Fig. 2. Two-dimensional gel electrophoresis and Western blotting of urea/ Nonidet P-40-extracted proteins of Globodera rostochiensis. Isoelectric focusing was done in an immobilized $\mathrm{pH}$ gradient ( $\mathrm{pH} 3$ to 10). In the second dimension, a linear sodium dodecyl sulfate-polyacrylamide gradient ( 8 to $18 \%$ ) was used. The part of the Western blot that showed labeling with antibody MGR48 is depicted. 
$\mathrm{mM}$ iodoacetoamide, and $0.025 \%$ (wt/vol) bromophenol blue; and were separated by second-dimension electrophoresis in an 8 to $18 \%$ (wt/vol) SDS-PAGE gradient gel (ExcelGel $110 \times 245 \times 0.5$ $\mathrm{mm}$, Pharmacia). The SDS-PAGE gel was used for semidry Western blotting on polyvinylidene difluoride (PVDF) membrane at $0.8 \mathrm{~mA} / \mathrm{cm}^{2}$ for $1 \mathrm{~h}$.

Induction and collection of stylet secretions. Unless otherwise stated, PRD-hatched preparasitic $\mathrm{J}_{2}$ were used for induction of stylet secretions. For each replicate, an estimated 20,000 preparasitic $\mathrm{J}_{2}$ were collected and exposed overnight to $4 \mathrm{ml}$ of a test solution at $20^{\circ} \mathrm{C}$.

To investigate the effect of DMT (Research Biochemicals, Natick, MA) and the $\mathrm{pH}$ of the incubation medium, DMT was dissolved to a final concentration of $6.5 \mathrm{mM}$ in tap water, $10 \mathrm{mM}$ glycine buffer (pH 3.5 and 10), or $10 \mathrm{mM}$ Tris- $\mathrm{HCl}$ buffer ( $\mathrm{pH} 8.0$ ). In control solutions, DMT was omitted. When appropriate, $0.01 \%$ Coomassie brilliant blue G-250 (CBB G-250) was added to enhance the visibility and collection of stylet precipitates $(5,14)$.

To test the effect of hatching conditions on the production of stylet secretions, either tap water- or PRD-hatched $\mathrm{J}_{2}$ were incubated in standard pore water-based solutions. Standard-pore water was used to simulate natural conditions for nematodes in vitro. Standard-pore water contains $0.1 \mathrm{mM} \mathrm{KCl}, 0.2 \mathrm{mM} \mathrm{NaCl}, 0.35$ $\mathrm{mM} \mathrm{Ca}\left(\mathrm{NO}_{3}\right)_{2}, 0.3 \mathrm{mM} \mathrm{Mg}\left(\mathrm{NO}_{3}\right)_{2}$, and $0.3 \mathrm{mM} \mathrm{NH} \mathrm{NO}_{3}$ at $\mathrm{pH} 6$ (26). Standard-pore water was supplemented with a $20 \mathrm{mM}$ sodium phosphate solution ( $\mathrm{pH} \mathrm{6}$ ) to buffer the acidifying effect of DMT. In these experiments, the final DMT concentration was $4 \mathrm{mM}$.

Two methods were used to collect stylet secretions. For immunofluorescence testing with MGR48, precipitated stylet secretions were collected with a micropipette (Gilson Medical Electronics, Villiers-le-Bel, France). Alternatively, soluble stylet secretions were collected by shaking the $\mathrm{J}_{2}$ suspension vigorously on a whirl mixer followed by centrifugation at $10,000 \times g$ for $5 \mathrm{~min}$. The supernatant contained the solubilized stylet secretions and was checked with a dissecting microscope for the absence of $\mathrm{J}_{2}$. Secretions were processed either for denaturing Western blotting or for native dot blotting.

Incubation fluids with solubilized stylet secretions were concentrated for Western blotting at $4^{\circ} \mathrm{C}$ with a $1.5-\mathrm{ml}$ microcentrifuge ultrafiltration unit with a molecular mass cut-off of $5 \mathrm{kDa}$ (Ultrafree MC, Millipore Corp., Bedford, MA). The samples were concentrated from $4 \mathrm{ml}$ to a final volume of $10 \mu \mathrm{l}$ per sample and were supplemented with an equal volume of SDS sample buffer. After the addition of the protease inhibitors Pefabloc $(1 \mathrm{mM})$, trans-epoxysuccinyl-L-leucylamido-(4-guanidino)butane $(2.8 \mu \mathrm{M})$, EDTA $\cdot \mathrm{Na}_{2}(0.1 \mathrm{mM})$, and pepstatin $\mathrm{A}(0.15 \mu \mathrm{M})$, samples were stored at $-20^{\circ} \mathrm{C}$ until use.

Western and dot blotting. Semidry Western blotting and immunodetection were performed as described by De Boer et al. (8). For dot blot assays, $2 \mathrm{ml}$ of native solubilized stylet secretion was concentrated on a nitrocellulose blotting membrane under mild vacuum (Schleicher \& Scheull, Dassel, Germany). Subsequently, the dot blot was left to dry and processed for immunodetection as described previously (8). In this experiment, MAb MGR48 hybridoma culture supernatant, diluted 1:40 in phosphate-buffered saline (PBS)-0.1\% (vol/vol) Tween 20 (PBS pH 7.2: $150 \mathrm{mM} \mathrm{NaCl} ; 2.6$ $\mathrm{mM} \mathrm{KCl} ; 8.1 \mathrm{mM} \mathrm{Na}_{2} \mathrm{HPO}_{4}$; and $2.65 \mathrm{mM} \mathrm{KH}_{2} \mathrm{PO}_{4}$ ), was used as the primary antibody. Control blots were obtained by omitting the primary antibody.

To determine whether MAb MGR48 was directed to a carbohydrate epitope, periodic acid treatment of Western blots was performed according to Woodward et al. (31). The control lanes were kept in $50 \mathrm{mM}$ sodium acetate buffer $(\mathrm{pH} 4.5)$, whereas the experimental lanes were exposed to $1,5,10$, and $50 \mathrm{mM}$ periodic acid in sodium acetate buffer ( $\mathrm{pH} 4.5)$ in the dark for $90 \mathrm{~min}$. Control and experimental strips were rinsed with sodium acetate buffer ( $\mathrm{pH} 4.5)$ and incubated for $30 \mathrm{~min}$ in $50 \mathrm{mM}$ sodium borohydride in PBS.
A

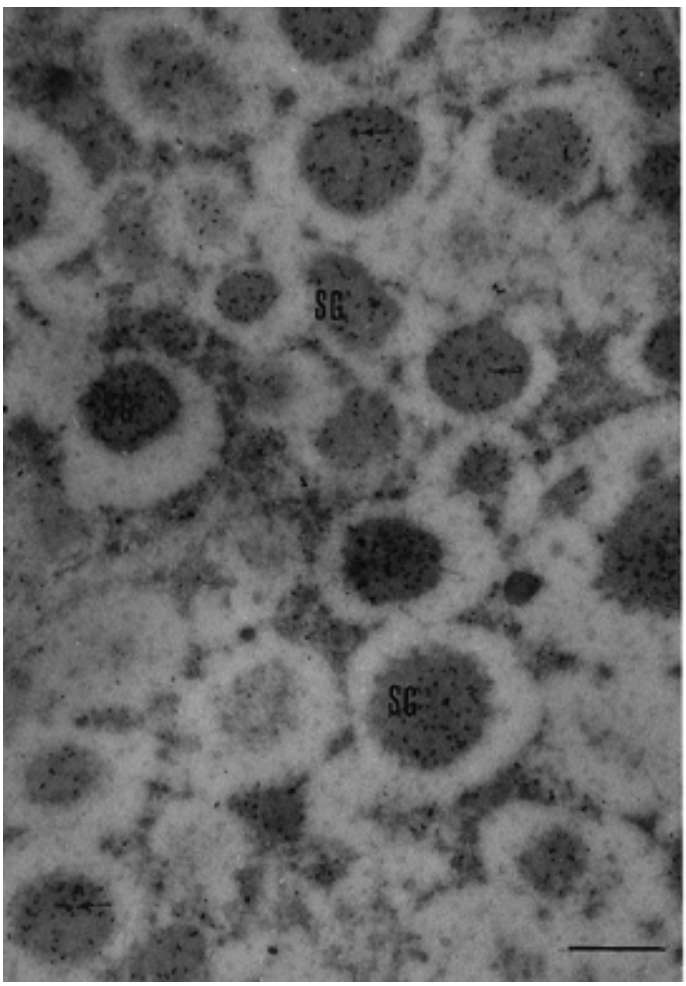

B

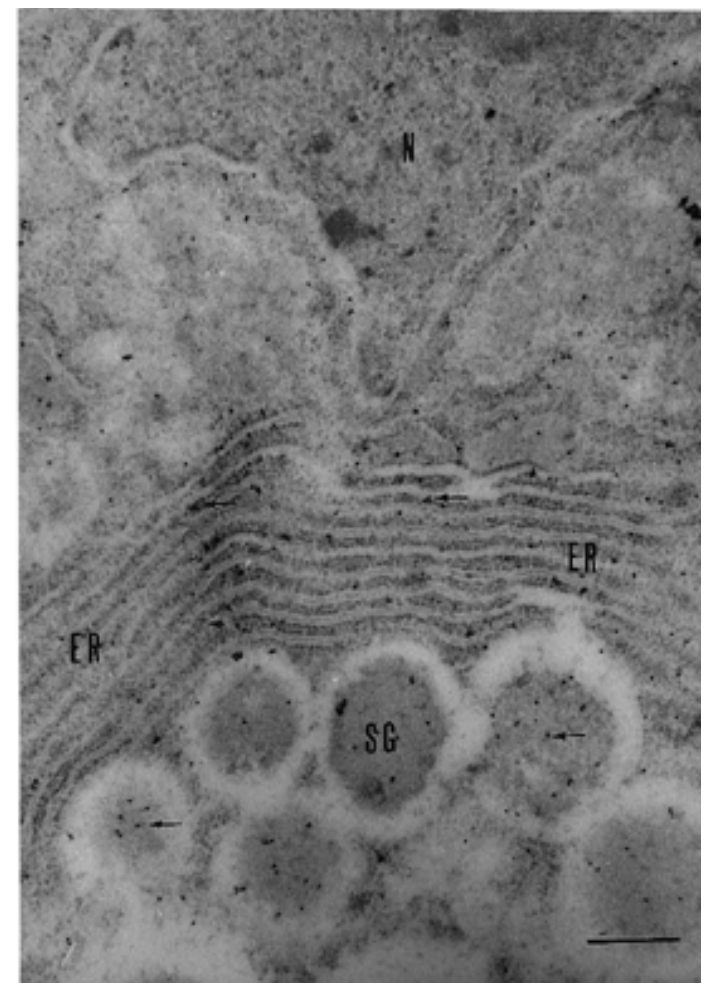

Fig. 3A and B. Immunogold labeling of the subventral esophageal gland cell of a second-stage juvenile of Globodera rostochiensis with monoclonal antibody MGR48. The gold particles (indicated by arrows) localized to A, the dense core of the secretory granules (SG) and $\mathbf{B}$, the rough endoplasmic reticulum (ER) surrounding the nucleus $(\mathrm{N})($ bars $=400 \mathrm{~nm})$. 
Indirect immunofluorescence microscopy. Indirect immunofluorescence microscopy of preparasitic $\mathbf{J}_{2}$ was performed similar to the method of De Boer et al. (8). CBB G-250-stained stylet secretions were collected by micropipette and used for indirect immunofluorescence microscopy as described previously $(5,14)$, with the following modifications. Stylet secretions were dried on no. 24 multiwell glass slides, instead of using dialysis membranes,

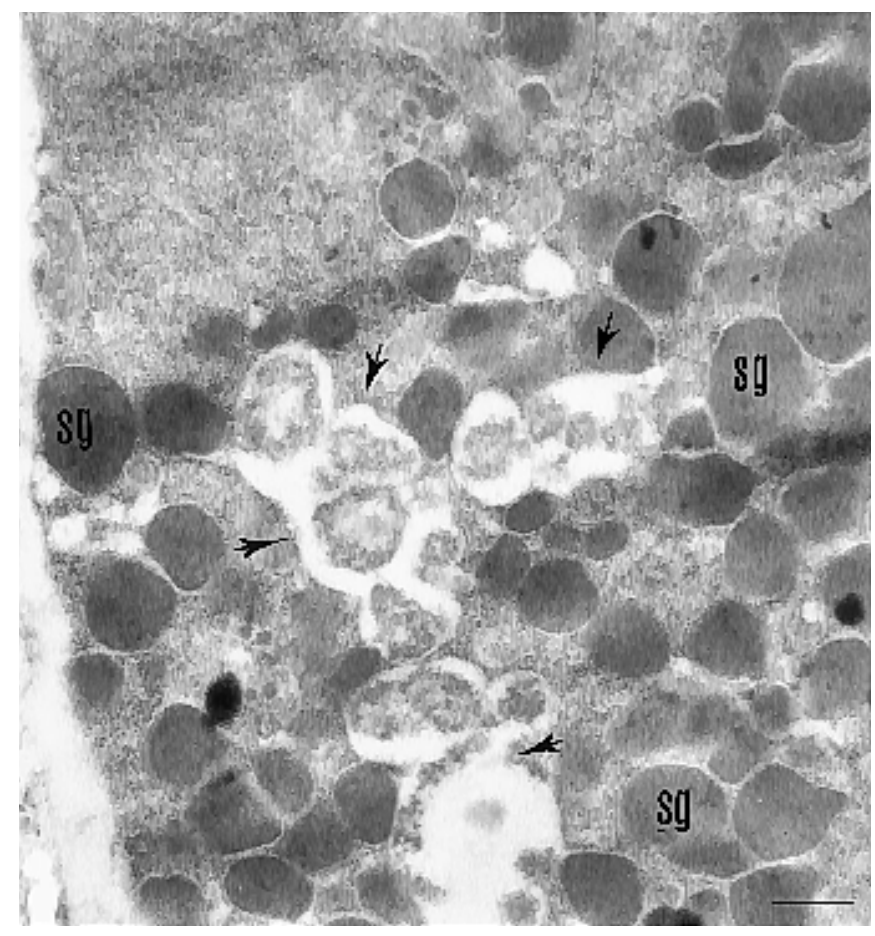

Fig. 4. Electron micrograph of the dorsal esophageal gland cell in Globodera rostochiensis after treatment with $6.5 \mathrm{mM} 5$-methoxy- $N, N$-dimethyltryptamine-hydrogen-oxalate. Translucent structures (arrows) appear among the typical electron-dense secretory granules (SG) of the dorsal esophageal gland (bar $=400 \mathrm{~nm})$.

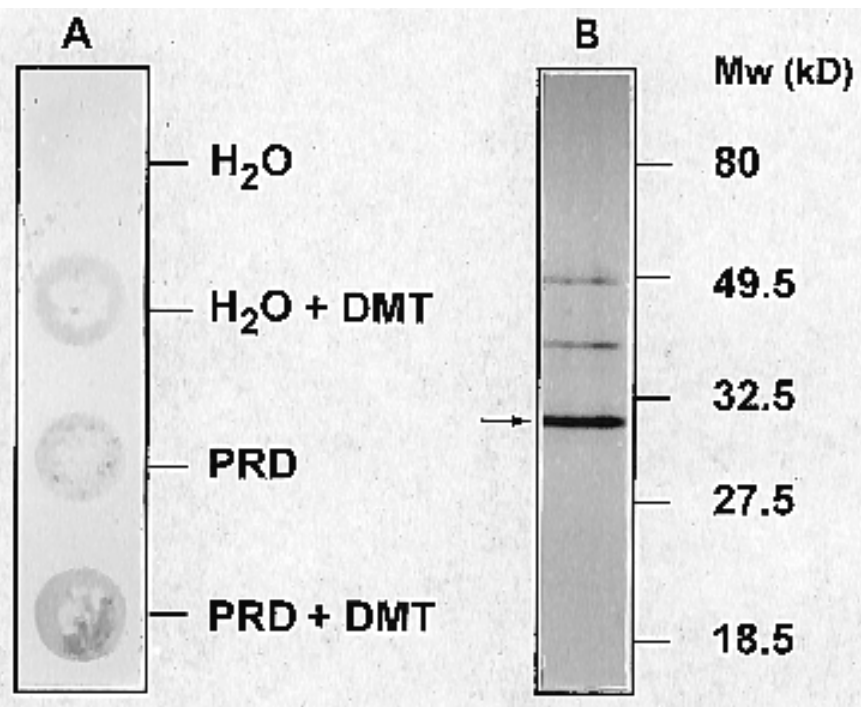

Fig. 5. Concentrated solubilized stylet secretions of Globodera rostochiensis tested with monoclonal antibody MGR48 on Western blot and dot blot. A, A dot blot of concentrated incubation fluids of second-stage juveniles $\left(\mathrm{J}_{2}\right)$ either hatched in tap water $\left(\mathrm{H}_{2} \mathrm{O}\right)$ or potato root diffusate (PRD) after $24 \mathrm{~h}$ in buffered standard-pore water (described in text). B, Western blot of concentrated incubation fluid of PRD-hatched $J_{2}$ after an incubation period of $24 \mathrm{~h}$ in standard-pore water. The $31-\mathrm{kDa}$ protein band is the predominating antigen in stylet secretions. The addition of 5-methoxy- $N, N$-dimethyltryptamine-hydrogenoxalate to a final concentration of $4 \mathrm{mM}$ is indicated as DMT. and were blocked with $10 \mu \mathrm{l}$ of $1 \%$ (wt/vol) BSA in PBS for 10 min before antibody treatments.

Immunoelectron microscopy. $G$. rostochiensis preparasitic $\mathbf{J}_{2}$ were fixed either in $2 \%(\mathrm{wt} / \mathrm{vol})$ paraformaldehyde and $1 \%$ (vol/ vol) glutaraldehyde or in $2 \%$ (wt/vol) paraformaldehyde and were embedded in LR White resin (London Resin Co. Ltd., Basingstoke, England) (8). Thin roots of potato (Solanum tuberosum subsp. tuberosum cv. Bintje) were inoculated with G. rostochiensis (30). Parasitic $\mathrm{J}_{2}$ were observed within infected pieces of thin translucent potato roots and fixed and embedded in LR Gold resin (London Resin) 5 to 7 days after inoculation (29).

For immunogold labeling, thin sections (50 to $80 \mathrm{~nm}$ ) were collected on nickel square-mesh grids coated with $0.6 \%$ (wt/vol) Formvar. The labeling was performed on $30-\mu$ drops at room temperature as follows: $20 \mathrm{~min}$ on $50 \mathrm{mM}$ glycine in PBS (pH 7.2), 30 $\min$ on $0.2 \%$ (vol/vol) BSA-C (Aurion, Wageningen, the Netherlands) in PBS, $2 \mathrm{~h}$ on MAb hybridoma supernatant (diluted $1: 20$ in $0.2 \%$ [vol/vol] BSA-C in PBS), 6 washes of 5 min each with $0.2 \%$ (vol/vol) BSA-C in PBS, $2 \mathrm{~h}$ on goat anti-mouse immunoglobulin $\mathrm{G}(\mathrm{IgG})(\mathrm{H}+\mathrm{L})$ conjugated with $10 \mathrm{~nm}$ colloidal gold (Aurion) diluted $1: 20$ with $0.2 \%$ ( $\mathrm{vol} / \mathrm{vol}) \mathrm{BSA}-\mathrm{C}$ in PBS, 4 washes of 5 min each with $0.2 \%$ (vol/vol) BSA-C in PBS, 3 washes of $5 \mathrm{~min}$ each with PBS, 5 min on $2 \%$ (vol/vol) glutaraldehyde (EM grade, Agar Scientific, Essex, England) in PBS, and 5 washes of $5 \mathrm{~min}$ with distilled water. Except for the colloidal gold conjugate solution, all solutions were filtrated before use $(0.22 \mu \mathrm{m}$; Millipore Corp.). In control sections, the primary antibody was omitted or replaced by an irrelevant MAb of known specificity. Poststaining was done with $2 \%$ (wt/vol) aqueous uranyl acetate and lead citrate (23).

\section{RESULTS}

Electrophoretic characterization of svp's. SDS-extracted proteins from homogenized preparasitic $\mathrm{J}_{2}$ were separated by SDSPAGE. The monoclonal antibody MGR48 identified three protein bands (svp31, svp39, and svp49) on Western blots, both under reducing (Fig. 1, lane 1) and nonreducing conditions (data not shown). Presumably due to a homogenization procedure that differed from that used by De Boer et al. (8), svp30 could not be detected on one-dimensional Western blot in our experiments. Oxidation of carbohydrate side chains with a range of periodic acid concentrations (1 to $50 \mathrm{mM}$ ) did not have any effect on the binding pattern of MGR48 on Western blot (Fig. 1, lane 2).

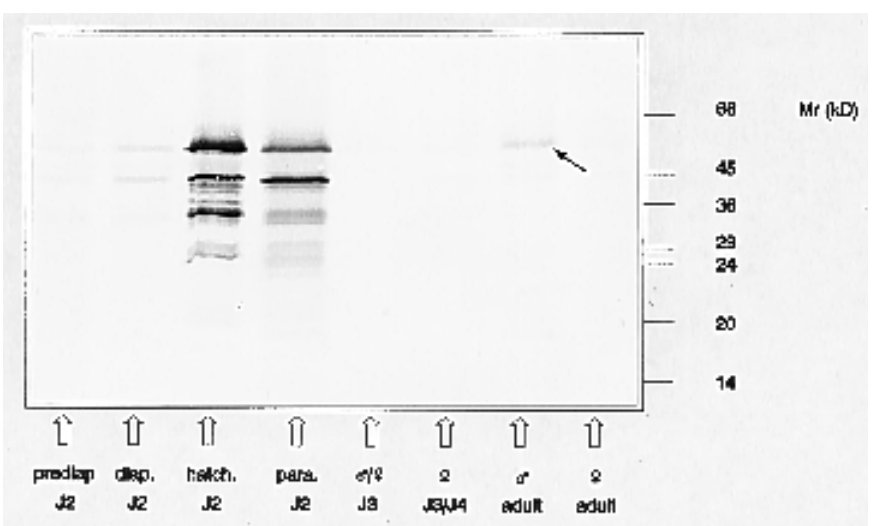

Fig. 6. Western blot of sodium dodecyl sulfate-extracted proteins from various life stages of Globodera rostochiensis. Immunodetection was done with monoclonal antibody MGR48. Prediap. $\mathrm{J}_{2}=$ eggs containing young secondstage juveniles; diap. $\mathbf{J}_{2}=$ eggs containing $\mathbf{J}_{2}$ in diapause; hatch. $\mathbf{J}_{2}=$ newly hatched $\mathrm{J}_{2}$ in potato root diffusate; para. $\mathrm{J}_{2}=$ parasitic $\mathrm{J}_{2}$ isolated from infected potato roots; $\delta / \rho_{+} \mathbf{J}_{3}=$ isolated third-stage parasitic juveniles, males and females; $q \mathbf{J}_{3} / \mathbf{J}_{4}=$ mixed sample of isolated third- and fourth-stage parasitic females; 0 adult $=$ isolated adult males; and $q$ adult $=$ isolated adult females. The minor signal detected in adult males is indicated by an arrow. 
Six protein spots were detected with MGR48 when protein extracts of preparasitic $\mathrm{J}_{2}$ were separated with two-dimensional electrophoresis and electroblotted on PVDF membrane (Fig. 2). Svp30 focused at $\mathrm{pH} 7.6$, whereas svp31 focused as two isoelectric point variants, pI 7.6 and 7.9. A new protein species (svp32), which was not separated on one-dimensional Western blots previously (8), appeared at pI 6.8 and $32 \mathrm{kDa}$. Svp39 focused at pI 7.3 in the applied $\mathrm{pH}$ range, and svp49 focused at $\mathrm{pI} 8.7$.

Secretion of svp's. Immunogold-labeling experiments on thin sections of aldehyde-fixed preparasitic PRD-hatched $\mathrm{J}_{2}$ with MGR48 revealed clearly a specific concentration of gold particles within the matrix of secretory granules of the subventral esophageal gland cells (Fig. 3A). MGR48 also bound within the lumen of rough endoplasmic reticulum surrounding the nucleus of the subventral gland cells (Fig. 3B). Localization in smaller subcellular organelles, such as a Golgi body, was not possible due to poor preservation of the ultrastructure.

Substantial quantities of precipitated stylet secretion from preparasitic $\mathrm{J}_{2}$ were obtained when the $\mathrm{J}_{2}$ were exposed to $6.5 \mathrm{mM}$ DMT. In an indirect immunofluorescence assay, MAb MGR48 labeled the DMT-induced stylet secretions (data not shown). No CBB G-250-stained secretions or excretions from the amphids, excretory/secretory pore, or rectal glands were observed in DMT assays. Although no secretory granule movement in the esophageal glands or metacorpal activity was observed, the use of DMT was strongly correlated with stylet thrusting.

Indirect immunofluorescence with MGR48 was used to compare DMT-treated and nontreated preparasitic PRD-hatched $\mathrm{J}_{2}$. A more granular, less intense labeling of the subventral esophageal glands was observed in DMT-treated $\mathbf{J}_{2}$, suggesting a decrease in gland content (data not shown). Immunogold electron microscopy of DMT-exposed $\mathrm{J}_{2}$ confirmed these observations. Both the dorsal and subventral esophageal glands contained considerably fewer secretory granules compared to the control nematodes. Secretory granules were stacked in the extension and ampulla regions of the gland cells. Fusion of individual secretory granules to more translucent structures was observed among the typical homogeneous electrondense granules in the cell body of the dorsal esophageal gland (Fig. 4).
The precipitation of stylet secretions observed at the lip region when exposed to DMT appeared to be $\mathrm{pH}$ dependent and not due to the effect of DMT itself. DMT tends to acidify the solution $(\mathrm{pH}$ 3.5 to 4 in distilled water at room temperature), and no particulates were observed when more alkaline buffers $(\mathrm{pH}>5.5)$ were used. These observations were confirmed by incubation of PRDhatched $\mathrm{J}_{2}$ in various acidic buffers $(\mathrm{pH}<5.5)$ without DMT. All acidic buffers tested resulted in precipitation of secretions at the stylet tip.

Testing the effect of different hatching conditions showed that, apart from stimulation of hatching, PRD also triggers the secretion of svp's. Incubation of tap water-hatched $\mathrm{J}_{2}$ in standard-pore water did not result in the secretion of svp's at a detectable level on dot blots with MGR48 (Fig. 5A). In contrast, substantial quantities of svp's were detected on dot blot when PRD-hatched $\mathrm{J}_{2}$ were used.

DMT supplemented with incubation fluid (standard-pore water) resulted in an additional effect on secretion of svp's. DMT stimulated secretion of svp's by tap water-hatched $\mathrm{J}_{2}$. Secretion of svp's was increased further if PRD-hatched $\mathrm{J}_{2}$ were used instead of tap water-hatched $\mathbf{J}_{2}$. Exposure of $\mathbf{J}_{2}$ to DMT did not harm the nematodes irreversibly; they were still able to infect potato roots and develop into adult females (data not shown).

One-dimensional Western blotting revealed that three svp's (31, 39 , and $49 \mathrm{kDa}$ ) were present in standard-pore water when PRDhatched $\mathrm{J}_{2}$ were used. Among these proteins, svp31 was predominant (Fig. 5B).

Developmental regulation of svp's. Developmental regulation of svp's throughout the nematode's life cycle was determined by Western blot analysis (Fig. 6). The protein content of each nematode extract was estimated, and equal protein quantities from each developmental stage were analyzed. The svp's were hardle detectable in fresh eggs containing young $\mathbf{J}_{2}$ or in dry eggs containing $\mathbf{J}_{2}$ in diapause. Maximum immunodetection of svp's occurred in homogenates from preparasitic PRD-hatched $\mathbf{J}_{2}$ from dried cysts that had passed the diapause. The staining intensity of svp31/32 decreased in parasitic $\mathbf{J}_{2}$, whereas in this stage no substantial decrease was observed for svp39 and svp49 (Fig. 6). None of the three svp's could be detected in other juvenile

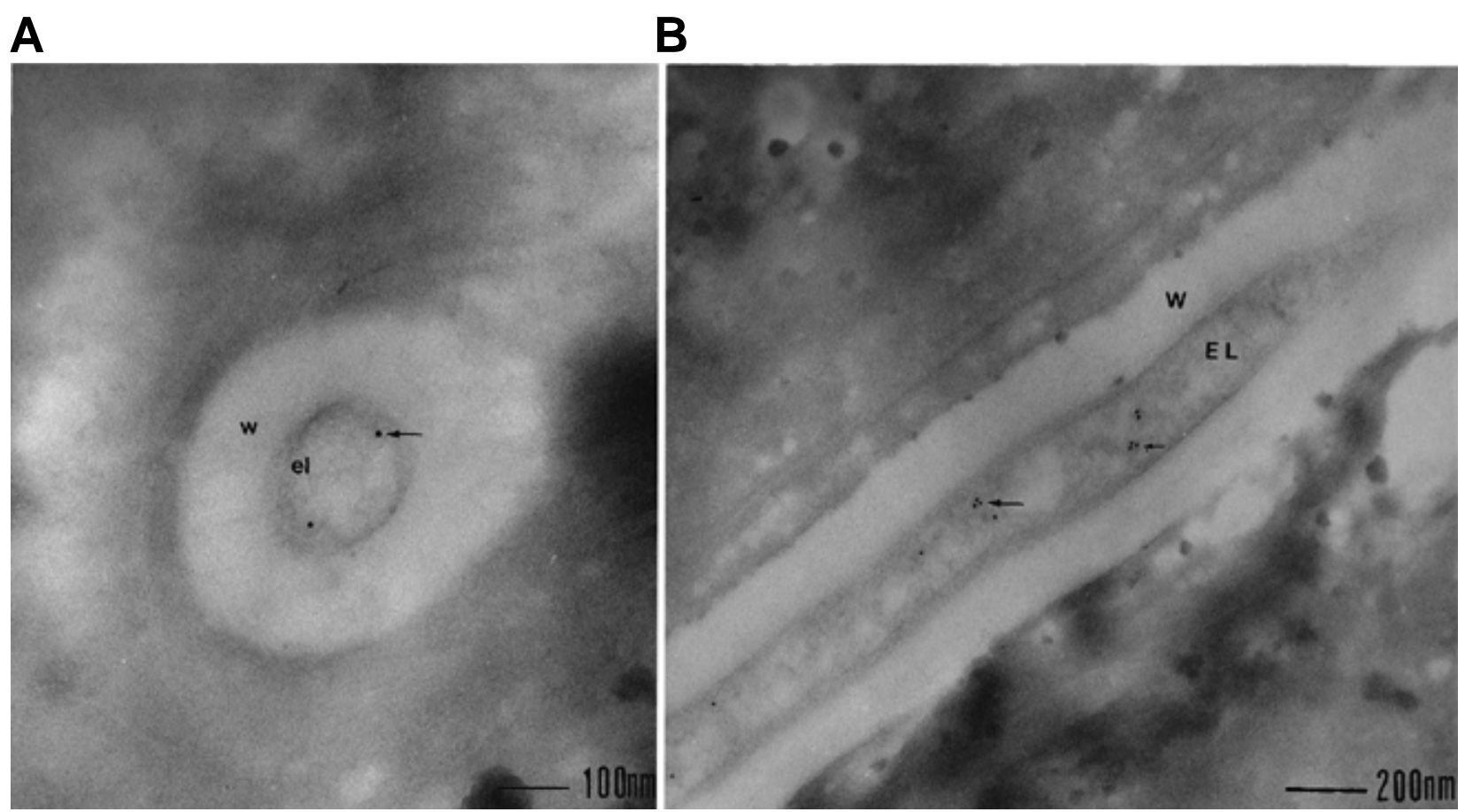

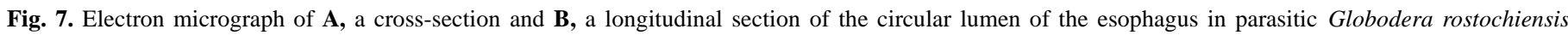

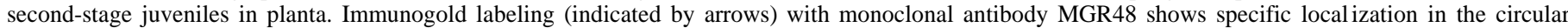
lumen (el or EL) of the esophagus (procorpus; $\mathrm{w}$ or $\mathrm{W}=$ cuticularized esophageal wall). 
stages and adult females. A minor quantity of svp49 was observed in adult males.

The size of the subventral esophageal glands changes throughout the life cycle, and the total protein content increases during the later life stages. For example, the total protein content of adult females is about 300 times higher compared to preparasitic $J_{2}$. To exclude the possibility that the apparent absence of svp's in stages other than $\mathrm{J}_{2}$ was due to dilution from increasing total protein contents, an additional SDS-PAGE gel was heavily overloaded with protein extracts of parasitic stages. No specific changes were detected on Western blot compared to Figure 6.

Immunogold labeling of parasitic $\mathbf{J}_{\mathbf{2}}$ in planta. Potato roots infected with $\mathrm{J}_{2}$ were used to study the secretion of the subventral gland proteins during the early events of plant parasitism. The impermeability of the cuticle usually prevents infiltration of LR Gold resin in parasitic $\mathbf{J}_{2}$ inside plants tissue. As a consequence, the nematodes shrink after polymerization of the resin, and soft tissue in the nematode shows morphological distortion. However, in some cases the cuticularized lumen of the esophagus remained well preserved in thin sections. Serial sections of the esophagus showed immunogold labeling of svp antigens within the circular lumen of the esophagus anterior to the metacorpal pump chamber (procorpus) (Fig. 7). Using MGR48, the labeling intensity was not strong but was very specific to esophageal lumen both in cross (Fig. 7A) and longitudinal (Fig. 7B) sections.

\section{DISCUSSION}

The subventral esophageal glands of the potato cyst nematode G. rostochiensis contain basic proteins (svp). On two-dimensional electrophoresis, five of six svp's focused in the basic part of the immobilized $\mathrm{pH}$ gradient. Oxidation of carbohydrate epitopes with periodic acid is one means of detecting whether a MAb is directed to a carbohydrate moiety of a glycoprotein (31). Because periodic acid oxidation did not change the binding pattern of MGR48 on Western blot, the epitope of MGR48 is not of a carbohydrate nature. Therefore, we conclude that the epitope of MGR48 is either a conserved stretch of amino acid residues present in distinct protein species or that MGR48 recognizes successive stages of posttranslational protein processing.

It has been argued (34) that the metacorporal pump chamber of the beet cyst nematode $H$. schachtii forms an anatomical barrier that precludes the secretion of subventral esophageal gland proteins into the plant. However, apart from stimulation of hatching, PRD stimulates the secretion of svp's through the stylet of the potato cyst nematode G. rostochiensis. svp31 was predominant in the collected stylet secretions, and this finding could indicate that this protein is the final, biologically active form. During secretion in vitro, no activity was observed in the pump chamber.

Immunogold labeling in the lumen of the esophagus (procorpus) in parasitic $\mathrm{J}_{2}$ in planta with MGR48 also indicated that svp's of G. rostochiensis are transported anterior to the metacorpal pump chamber. These data from preparasitic and parasitic $\mathrm{J}_{2}$ under relatively natural conditions suggest that svp's are secreted through the stylet into plant tissue.

Under natural conditions, a $\mathbf{J}_{2}$ has to migrate from the egg toward the roots of a host plant. Presumably, secretion of svp's during this period would be nonfunctional. Our results could suggest that preparasitic $\mathrm{J}_{2}$ that hatch in the vicinity of potato roots would begin to secrete svp's in the soil. However, in our experiments eggs were exposed to PRD at a high concentration, which is unlikely to exist in soil except in the immediate vicinity of the roots of a host plant. Therefore, we assume that preparasitic $\mathrm{J}_{2}$ do not secrete svp's under natural conditions until the moment at which a root of a host plant is reached.

Until now, exposure to DMT was the most obvious means of inducing secretion of esophageal gland proteins in cyst nematodes (14). In the case of potato cyst nematodes, svp-containing stylet secretions can be induced in $\mathbf{J}_{2}$ from eggs hatched in PRD. DMT has an additional stimulatory effect on svp secretion. With respect to the observed forward flow of svp's, our data agree with previously published data on the flow of the chemically induced secretion of svp's in H. glycines (14) and M. incognita (5). However, the observation that these stylet secretions precipitate at the lip region requires further investigation. For potato cyst nematodes $\left(J_{2}\right)$, we showed that the precipitation of stylet secretions does not occur above $\mathrm{pH}$ 5.5.

The expression of svp's in potato cyst nematodes is developmentally regulated. Interestingly, the predominance of svp31 in concentrated incubation fluids after incubation of preparasitic $\mathbf{J}_{2}$ for $24 \mathrm{~h}$ gives the lowest immunodetection in homogenates of parasitic $\mathrm{J}_{2}$. Most svp's were detectable in preparasitic and parasitic $\mathbf{J}_{2}$ but not in $\mathbf{J}_{3}, \mathbf{J}_{4}$, or females. Presumably, the svp's most likely play a role in the early events of the plant-nematode interaction. From this perspective, they may either be involved in cell-wall breakdown during the migratory process (27) or in feeding site induction (28). The svp's apparently are not involved in feedingsite maintenance. The increased expression of the svp's in adult males is remarkable. Contrary to $\mathbf{J}_{3}, \mathbf{J}_{4}$, and females, adult males are mobile and can leave the root. Expression of svp's in adult males would favor the hypothesis that svp's are involved in the migratory process. Our findings agree with previous findings of accumulation of secretory granules in the subventral esophageal glands of males in H. schachtii (34) and H. glycines (1).

The isolation and functional analysis of genes encoding secretory proteins from the esophageal glands is one of the major challenges in plant nematology. MAbs, in theory, provide a suitable starting point for isolating genes. A MAb directed against the esophageal glands was used to isolate a cDNA clone from a $M$. incognita expression library (22). The cDNA sequence showed similarities with the rod portion of a myosin-heavy chain of various origins. It was hypothesized that the encoded protein plays a role in the intracellular movement of secretory proteins and is not involved in the host-parasite interaction.

Our results indicate that, in contrast to previous assumptions $(32,34)$, secretions from the subventral esophageal glands of cyst nematodes probably play a direct role in the host-parasite interaction, as was concluded earlier for root-knot nematodes (5). Analyzing various developmental stages strongly suggests that the svp's are involved in the early interaction events. Further purification and characterization of these svp's will be a major step forward toward understanding the interaction between plants and sedentary plant-parasitic nematodes.

\section{ACKNOWLEDGMENTS}

This research was supported by the Dutch Potato Board, the Netherlands Life Sciences Foundation, EC-Grant BIO2-CT 92.0239, and the Netherlands Technology Foundation under the coordination of the Life Sciences Foundation. Additional support was obtained from NATO Grant CRG 931004. We thank J. W. M. Van Lent and J. Groenewegen of the Department of Virology, Wageningen Agricultural University, Wageningen, the Netherlands, for offering electron microscope facilities.

\section{LITERATURE CITED}

1. Baldwin, J. G., Hirschmann, H., and Triantaphyllou, A. C. 1977. Comparative fine structure of the oesophagus of males of Heterodera glycines and Meloidogyne incognita. Nematologica 23:768-776.

2. Bradford, M. M. 1976. A rapid and sensitive method for the quantitation of microgram quantities of protein utilizing the principle of protein-dye binding. Anal. Biochem. 72:248-254.

3. Clarke, A. J., and Perry, R. N. 1977. Hatching of cyst-nematodes. Nematologica 23:350-368.

4. Curtis, R. H. C. 1996. Identification and in situ and in vivo characterization of secreted proteins produced by plant-parasitic nematodes. Parasitology 113:589-597.

5. Davis, E. L., Allen, R., and Hussey, R. S. 1994. Developmental expression of esophageal gland antigens and their detection in stylet secretions 
of Meloidogyne incognita. Fundam. Appl. Nematol. 17:255-262.

6. Davis, E. L., Aron, L. M., Pratt, L. H., and Hussey, R. S. 1992. Novel immunization procedures used to develop monoclonal antibodies that bind to specific structures in Meloidogyne spp. Phytopathology 82:12441250 .

7. De Boer, J. M., Overmars, H. A., Bakker, J., and Gommers, F. J. 1992. Analysis of two-dimensional protein patterns from developmental stages of the potato cyst-nematode, Globodera rostochiensis. Parasitology 105: 461-474.

8. De Boer, J. M., Smant, G., Goverse, A., Davis, E. L., Overmars, H. A., Pomp, H., Van Gent-Pelzer, M., Zilverentant, J. F., Stokkermans, J. W. P. G., Hussey, R. S., Gommers, F. J., Bakker, J., and Schots, A. 1996. Secretory granule proteins from the esophageal glands of the potato cyst nematode identified by monoclonal antibodies to a protein fraction from second stage juveniles. Mol. Plant Microb. Interact. 9:39-46.

9. Doncaster, C. C. 1971. Feeding in plant parasitic nematodes: Mechanism and behavior. Pages 137-157 in: Plant Parasitic Nematodes, vol. 2. B. M. Zuckerman, W. F. Mai, and R. A. Rohde, eds. Academic Press, New York.

10. Endo, B. Y. 1971. Synthesis of nucleic acids at infection sites of soybean roots parasitized by Heterodera glycines. Phytopathology 61:395-399.

11. Endo, B. Y. 1984. Ultrastructure of the esophagus of larvae of the soybean cyst nematode, Heterodera glycines. Proc. Helminthol. Soc. Wash. 51:1-24.

12. Endo, B. Y. 1987. Ultrastructure of esophageal gland secretory granules in juveniles of Heterodera glycines. J. Nematol. 19:469-483.

13. Gheysen, G., and Van Montagu, M. 1995. Plant/nematode interactions, a molecular biologist's approach. Nematologica 41:366-384.

14. Goverse, A., Davis, E. L., and Hussey, R. S. 1994. Monoclonal antibodies to the esophageal glands and stylet secretions of Heterodera glycines. J. Nematol. 26:251-259.

15. Hussey, R. S. 1989. Disease-inducing secretions of plant-parasitic nematodes. Annu. Rev. Phytopathol. 27:123-141.

16. Hussey, R. S., Paguio, O. R., and Seabury, F. 1990. Localization and purification of a secretory protein from the esophageal glands of $\mathrm{Mel}$ oidogyne incognita with a monoclonal antibody. Phytopathology 80:709-714.

17. Jones, M. G. K. 1981. Host cell responses to endoparasitic nematode attack: Structure and function of giant cells and syncytia. Ann. Appl. Biol. 97:353-372.

18. Jones, M. G. K., and Northcote, D. H. 1972. Nematode-induced syncytiumA multinucleate transfer cell. J. Cell Sci. 10:789-809.

19. McClure, M. A., and Von-Mende, N. 1987. Induced salivation in plantparasitic nematodes. Phytopathology 77:1463-1469.

20. Melillo, M. T., Bleve-Zacheo, T., and Zacheo, G. 1990. Ultrastructural response of potato roots susceptible to cyst nematode Globodera pallida pathotype Pa 3. Rev. Nematol. 13:17-28.

21. Niebel, A., Gheysen, G., and Van Montagu, M. 1994. Plant-cyst nematode and plant root-knot nematode interactions. Parasitol. Today 10:424-
430.

22. Ray, C., Abbott, A. G., and Hussey, R. S. 1994. Trans-splicing of a Meloidogyne incognita mRNA encoding a putative esophageal gland protein. Mol. Biochem. Parasitol. 68:93-101.

23. Reynolds, E. S. 1963. The use of lead citrate at high $\mathrm{pH}$ as an electronopaque stain in electron microscopy. J. Cell Biol. 17:208-212.

24. Rice, S. L., Leadbeater, B. S. C., and Stone, A. R. 1985. Changes in cell structure in roots in resistant potatoes parasitized by potato cyst-nematodes. I. Potatoes with resistance gene H1 derived from Solanum tuberosum ssp. andigena. Physiol. Plant Pathol. 27:219-234.

25. Roosien, J., Van Zandvoort, P. M., Folkertsma, R., Rouppe-Van der Voort, J. N. A. M., Goverse, A., Gommers, F. J., and Bakker, J. 1993. Single juveniles of the potato cyst nematodes Globodera rostochiensis and $G$. pallida differentiated by randomly amplified polymorphic DNA. Parasitology 107:567-572.

26. Schouten, A. J., and Van der Brugge, I. R. 1989. Acute toxiciteit van aluminium en $\mathrm{H}^{+}$ionen concentratie voor bodemnematoden uit een zuur en kalkrijk dennebos. Rep. 718603001. National Institute of Public Health and Environmental Protection, Bilthoven, the Netherlands.

27. Steinbach, P. 1972. Untersuchungen uber das Verhalten von Larven des Kartoffelzystenalchens (Heterodera rostochiensis Wollenweber, 1923) an und in Wurzeln der Wirtpflanze Lycopersicon esculentum Mill. II. Das Eindringen von Kartoffelnematoden in die Wirtswurtzel. Biol. Zbl. 91: 743-756.

28. Steinbach, P. 1973. Untersuchungen uber das Verhalten von Larven des Kartoffelzystenalchens (Heterodera rostochiensis Wollenweber, 1923) an und in Wurzeln der Wirtspflanze Lycopersicon esculentum Mill. III. Die Nahrungsafname von Kartoffelnematodenlarven. Biol. Zbl. 92:563-582.

29. Van Lent, J. W. M., Groenen, J. T. M., Klinge-Roode, E. C., Rohrmann, G. F., Zuidema, D., and Vlak, J. M. 1990. Localization of the $34 \mathrm{kDa}$ polyhedron envelope protein in Spodoptera frugiperdi cells infected with Autographa californica nuclear polyhedrodrosis virus. Arch. Virol. 111: 103-114.

30. Van Haren, R. J. F. 1995. Application of dynamic energy budgets to xenobiotics kinetics in Mytilus edulis and population dynamics of Globodera pallida. Ph.D. thesis. Vrije Universiteit Amsterdam, Amsterdam.

31. Woodward, M. P., Young, W. W., and Bloodgood, R. A. 1985. Detection of monoclonal antibodies specific for carbohydrate epitopes using periodate oxidation. J. Immunol. Meth. 78:143-153.

32. Wyss, U. 1992. Observations on the feeding behaviour of Heterodera schachtii throughout development, including events during moulting. Fundam. Appl. Nematol. 15:75-89.

33. Wyss, U., and Grundler, F. M. W. 1992. Feeding behaviour of sedentary plant parasitic nematodes. Neth. J. Plant Pathol. 98 (Suppl. 2):165-173.

34. Wyss, U., and Zunke, U. 1986. Observations on the behaviour of second stage juveniles of Heterodera schachtii inside host roots. Rev. Nematol. 9:153-165. 